University of Nebraska - Lincoln

DigitalCommons@University of Nebraska - Lincoln

$11-16-1990$

\title{
The Pacific/ North American Teleconnection Pattern and United States Climate. Part I: Regional Temperature and Precipitation Associations
}

Daniel J. Leathers

Brent Yarnal

Michael A. Palecki

Follow this and additional works at: https://digitalcommons.unl.edu/natrespapers

Part of the Natural Resources and Conservation Commons, Natural Resources Management and Policy Commons, and the Other Environmental Sciences Commons

This Article is brought to you for free and open access by the Natural Resources, School of at DigitalCommons@University of Nebraska - Lincoln. It has been accepted for inclusion in Papers in Natural Resources by an authorized administrator of DigitalCommons@University of Nebraska - Lincoln. 


\title{
The Pacific/North American Teleconnection Pattern and United States Climate. Part I: Regional Temperature and Precipitation Associations
}

\author{
DANIEL J. LeATHERS \\ Meteorology/Climatology Program, Department of Geography, University of Nebraska-Lincoln, Lincoln, Nebraska \\ BRENT YARNAL \\ Department of Geography, Earth System Science Center, The Pennsylvania State University, University Park, Pennsylvania \\ Michael A. Palecki \\ Department of Geography, State University of New York at Buffalo, Amherst, New York \\ (Manuscript received 28 September 1989, in final form 16 November 1990)
}

\begin{abstract}
The Pacific/North American (PNA) teleconnection index, a measure of the strength and phase of the PNA teleconnection pattern, is related to the variations of the surface climate of the United States from 1947 through 1982 for the autumn, winter, and spring months when the PNA is a main mode of Northern Hemisphere midtropospheric variability. The results demonstrate that the PNA index is highly correlated with both regional temperature and precipitation. The strongest, most extensive correlations between the index and temperature are observed in winter, but large areas of the country show important associations during the spring and autumn as well. Although the centers of highest correlation migrate systematically with changes in the circumpolar vortex over the course of the annual cycle, the southeastern and northwestern parts of the United States possess consistently high index-temperature correlations.

Correlations between the PNA index and precipitation are weaker and less extensive than those for temperature, but large coherent regions of high correlations are observed across the nation. Winter and early spring exhibit the strongest relationships because spatially coherent synoptic-scale systems, related to the long-wave pattern, control precipitation. The late spring and early autumn seasons have the least extensive and weakest correlations due to the importance of less organized smaller-scale convective rainfall events.
\end{abstract}

\section{Introduction}

Teleconnections are statistical associations among climatic variables separated by large distances. They are a consequence of the large-scale dynamics of the ocean and atmosphere linking disparate regional climates into one unified, global climatic system. The spatial and temporal aspects of teleconnections can be interpreted in terms of the large-scale dynamical structure of the atmosphere. Blackmon et al. (1984a,b) have studied the extratropical teleconnections of midtroposphere geopotential heights after applying low, intermediate, and high bandpass filters. This separation exposes the very different dynamical nature of these temporally distinct teleconnections: high-frequency features are clearly baroclinic in nature; intermediatefrequency patterns take the form of propagating Rossby wave trains; and low-frequency variations are domi-

Corresponding author address: Dr. Daniel J. Leathers, Meteorology/Climatology Program, Dept. of Geography, University of Nebraska, Lincoln, NE 68588-0135. nated by oceanic north-south dipole patterns. Some of the low-frequency patterns have been found to be related to the barotropic instability of the mean flow (Simmons et al. 1983; Frederikson and Bell 1987), although their exact nature is not completely understood (Wallace and Lau 1985). Also, internal atmospheric interactions of the mean flow with high- and low-frequency transients have been examined with the help of frequency-dependent teleconnections (Lau and Holopainen 1984; Wallace and Lau 1985; Nakamura et al. 1987; Lau 1988).

Observational examination of the external forcing of atmospheric variability by boundary-layer anomalies has progressed from the seminal works of Bjerknes $(1966,1969)$ and Namias $(1969,1976)$ to more recent studies that take advantage of the framework of tropical and extratropical teleconnections (e.g., Mo and Livezey 1986; Livezey and Mo 1987; Lau and Boyle 1987). Observational work has also inspired extensive theoretical studies of atmospheric responses to external forcing using diverse models (e.g., Hoskins and Karoly 1981; Webster 1981, 1982; Simmons 1982; Blackmon 
et al. 1983; Simmons et al. 1983; Lau and Lim 1984; Geisler et al. 1985; Lau 1985; Palmer and Mansfield 1986a, 1986b; Held and Kang 1987; Pitcher et al. 1988). The observational and modeling studies, taken together, demonstrate the important role that teleconnections play in understanding the large-scale variability of the extratropical atmosphere.

On interannual time scales, teleconnection patterns may be a product of externally forced excitation of barotropically unstable modes, rather than purely internal normal mode growth (Geisler et al. 1985). Esbensen (1984) has demonstrated that in many cases, there are considerable differences between intra- and interannual teleconnection patterns. An important exception to this is the Pacific/North American (PNA) teleconnection, which is present at all time scales from weeks to years (Blackmon et al. 1984b). The mode of atmospheric variation represented by the PNA pattern may be excited directly by a standing Rossby wave train emanating from an anomalous heating source in the central equatorial Pacific (Horel and Wallace 1981) or, as suggested by Lau and Boyle (1987), this mode may result from changes in the strength of the east Asian jet during times of anomalous SST. Because of its position at the exit region of the east Asian jet, this pattern may efficiently extract energy from the climatological mean flow (Nakamura et al. 1987) resulting in the growth of a barotropically unstable mode in the North Pacific sector.

Many of the teleconnection studies cited previously focused exclusively on the variability of the atmospheric circulation. However, it is well known that these mid- to upper-level tropospheric flow patterns are strongly related to surface temperature and precipitation (e.g., Klein and Kline 1984; Klein and Bloom 1987; Livezey and Barnston 1988; Yarnal and Leathers 1988). This is especially true considering the interactions between low-frequency teleconnections and stormtracks cited by Lau (1988). In short, teleconnections may be used to portray climatological relationships between the planetary-scale atmospheric circulation and surface climate, within the context of the theory, modeling and diagnostics of global climate dynamics.

To date, the main focus of teleconnections/surface climate research has centered on global temperature and precipitation anomalies associated with El NiñoSouthern Oscillation (ENSO) events. Such studies have investigated the effect of ENSO events on United States surface climate (Ropelewski and Halpert 1986) and on regional climates across the globe (Ropelewski and Halpert 1987, 1989; Kiladis and Diaz 1989). However, very little work has been published relating low-frequency midtropospheric variations to regional surface climates. O'Connor (1959) published a catalog of teleconnection patterns based on 5-day mean $700-\mathrm{mb}$ height anomalies located in the western portion of the Northern Hemisphere. However, associated tempera- ture and precipitation composites related to the teleconnections were never published. More recently, Gutzler et al. (1988) looked at patterns of interannual variability in the Northern Hemisphere 850 -mb temperature as they related to teleconnections in the 500 mb geopotential heights. In addition, several investigators have examined the effects of various teleconnections on particular regional climates (e.g., Emery and Hamilton 1985; Yarnal and Diaz 1986; Lamb and Peppler 1987; Yarnal and Leathers 1988).

In this study, we demonstrate that the interannual climate variations in large regions of the United States are strongly affected by and closely associated with variations in the global climatic system as evidenced by the PNA teleconnection pattern. In Part I (this paper), we create a climatology relating a PNA teleconnection index to United States surface climate for all months in which the PNA pattern is a major mode of atmospheric variation. These months include September, October, December, January, February, March, and April (Barnston and Livezey 1987). The months of November and May will also be included so that complete autumn and spring seasons can be used. There is some evidence that variability patterns similar to the PNA pattern exist in the 700-mb field over North America during both of these additional months (Leathers 1990). Before data and analytical techniques are addressed or results and conclusions are presented, the basic characteristics of the PNA teleconnection index will be reviewed.

\section{The Pacific/North American teleconnection pattern}

Distinct linkages between anomalies in the mid- to upper-tropospheric geopotential height fields over the North Pacific Ocean and North America have been known for many years. Investigators have studied these anomalies and their associated large-scale pressure correlations in a variety of contexts (e.g., Allen et al. 1940; Klein 1952; Namias 1978; Blackmon et al. 1979). However, it was Wallace and Gutzler (1981) that first identified this area of correlated heights as one of the strongest extratropical teleconnections: the PNA. Since then, the pattern has been recognized as a major mode of atmospheric variability over North America during the Northern Hemisphere winter (Simmons et al. 1983; Barnston and Livezey 1987). Temporally, the teleconnection is evident on both meteorological and climatological time scales, extending from periods of days, weeks, months, and seasons (Blackmon et al. 1984a,b) to decades (Yarnal and Leathers 1988). The spatial location of the teleconnection on time scales of months to seasons is a function of the position of the mean stationary waves. The resulting mean flow over the Pacific/North American sector is characterized by a trough in the east-central North Pacific, a ridge over the Rocky Mountains, and a trough over eastern North America. The PNA rep- 
resents departures from the mean flow with anomaly centers over the North Pacific, the Cordillera of northwestern North America, and the southeastern United States. It is best represented by geopotential height data from the mid- to upper-troposphere because the elevated landmass of the Cordillera destroys the coherency of the pressure and geopotential height fields at lower elevations (Blackmon et al. 1979).

A measure of the relative strength of the opposite extremes of the PNA can be constructed from a linear combination of standardized 700 -mb height anomalies $\left(Z^{*}\right)$ at the grid points nearest the anomaly field centers (Wallace and Gutzler 1981). The index used in this study was given in Yarnal and Diaz (1986) as

$$
\begin{aligned}
& \text { PNA }=\frac{1}{3}\left[-Z^{*}\left(47.9^{\circ} \mathrm{N}, 170.0^{\circ} \mathrm{W}\right)\right. \\
&\left.+Z^{*}\left(49.0^{\circ} \mathrm{N}, 111.0^{\circ} \mathrm{W}\right)-Z^{*}\left(29.7^{\circ} \mathrm{N}, 86.3^{\circ} \mathrm{W}\right)\right] .
\end{aligned}
$$

This differs from the index of Wallace and Gutzler (1981), which included a subtropical center. This center is omitted in the present study because we are interested in the wave energy propagating through the North American sector. It is this energy that will effect the surface climate across the United States. Moreover, the use of the tropical center may be appropriate when the PNA is excited by direct Rossby wave propagation from the tropical Pacific (Horel and Wallace 1981). However, this center may give spurious PNA index values if the barotropically unstable mode is excited by anomalies in the east Asian jet (Lau and Boyle 1987). The PNA index is constructed so that the meridional (minus-plus-minus wave train) extreme of the teleconnection produces positive values, while the zonal (plus-minus-plus wave train) extreme index values are negative (Fig. 1). Although the two extremes of this teleconnection may not be forced by similar boundary-layer anomalies (Pitcher et al. 1988), studies of midtropospheric variance over North America indicate that the two opposite extremes of this pattern account for a significant portion of the variance in this area (Barnston and Livezey 1987; Yarnal and Leathers 1988).

Table 1 shows the composited $700-\mathrm{mb}$ standardized heights at the three centers of action of the PNA index for positive and negative index extremes of plus or minus one standard deviation. Also included in Table 1 is the standard deviation of each composited value and comments on the nature of the 3-lobed PNA pattern during index extremes for each month. It is important to note that the PNA index value captures the classic 3-lobed structure of the PNA teleconnection in the "statistical mean" over the 36-year period. However, there are large interannual variations in the strength of individual pattern centers for a given index value (Table 1). In fact, the index may completely fail to represent the 3-lobed nature of the PNA pattern on

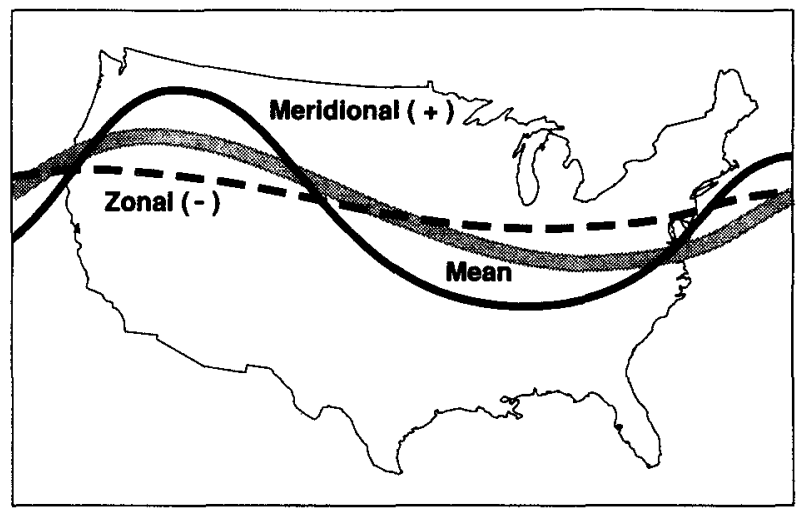

FIG. 1. Character of 700-mb flow over the United States for positive and negative values of the PNA index.

some rare occurrences. Thus, the correlation patterns discussed in sections 4 and 5 should be interpreted as the "average" relationship between the PNA pattern and United States temperature and precipitation. The patterns may not be representative of the relationship during a specific month.

\section{Data and methodologies}

The mean monthly 700-mb height data used to construct the monthly PNA index were collected for the period 1947 through 1982. Most of these data are from the National Meteorological Center (NMC) daily 700mb octagonal grid analyses (Jenne 1975), with some later points manually extracted from monthly mean 700 -mb charts. Temperature and precipitation data for the 48 coterminous United States are from the United States Divisional Climatic Data Set (NOAA 1983a,b). This dataset contains monthly mean temperature and precipitation values for all 344 climatic divisions for the period 1895 to 1983 and have been corrected for time of observation bias, station moves, etc., making them reliable for use in climatological studies (Karl et al. 1986).

The 700-mb data at the three grid points nearest the center of action of the PNA teleconnection were standardized by month and entered into Eq. (1) in order to compute a monthly value of the PNA index. Since temperatures usually approximate a normal distribution (Barry and Perry 1973), the temperature observations for each climatic division were standardized by month for the period of record (1947-1982) using the conventional $z$ transformation (Davis 1986).

Unlike temperature, however, understanding the importance of any one precipitation observation with respect to others for a given location is not always a straightforward problem. A simple averaging of precipitation amounts over time will produce a mean that may be dominated by the large anomalous precipita- 
TABLE 1. Composited 700-mb standardized heights for PNA index values of greater than or less than one standard deviation for each month. The table also gives the standard deviation of the monthly value (in parentheses) and comments on the robustness of the PNA pattern/index relationship for the month.

\begin{tabular}{|c|c|c|c|c|c|c|}
\hline Month & $\begin{array}{c}\text { Number of } \\
\text { cases }\end{array}$ & $48 / 170$ & $49 / 111$ & $30 / 86$ & Comments & \\
\hline Jan & 5 & $-1.53(0.27)$ & $1.47(0.77)$ & $-1.23(0.51)$ & both N.A. centers variable & \\
\hline Feb & 7 & $-1.27(0.46)$ & $1.31(0.68)$ & $-0.98(0.59)$ & both N.A. centers variable & \\
\hline Mar & 4 & $-1.30(0.65)$ & $1.31(0.67)$ & $-1.17(0.46)$ & Rocky Mt. center variable & \\
\hline Apr & 4 & $-1.20(0.49)$ & $1.13(1.01)$ & $-0.99(0.37)$ & Rocky Mt. center very variable & Positive Index \\
\hline May & 7 & $-0.66(0.55)$ & $0.80(0.52)$ & $-1.10(0.53)$ & Pacific and Rocky Mt. centers variable & +1 std dev \\
\hline Sep & 6 & $-1.32(0.75)$ & $1.10(0.28)$ & $-1.02(0.37)$ & all centers robust & \\
\hline Oct & 8 & $-0.57(0.72)$ & $1.06(0.68)$ & $-0.75(0.63)$ & Pacific center very variable & \\
\hline Nov & 7 & $-0.79(0.49)$ & $1.23(0.79)$ & $-1.04(0.68)$ & all centers variable & \\
\hline Dec & 4 & $-1.51(0.43)$ & $1.17(0.38)$ & $-1.06(0.55)$ & southeast center variable & \\
\hline Jan & 7 & $0.82(0.47)$ & $-0.81(0.61)$ & $1.09(0.72)$ & all centers variable & \\
\hline Feb & 8 & $1.22(0.24)$ & $-0.91(0.67)$ & $1.10(0.44)$ & Rocky Mt. center variable & \\
\hline Mar & 5 & $1.52(0.44)$ & $-0.73(0.63)$ & $1.21(0.08)$ & Rocky Mt. center variable & \\
\hline Apr & 5 & $1.39(0.62)$ & $-1.01(0.27)$ & $1.00(0.91)$ & southeast center variable & Negative Index \\
\hline May & 7 & $0.99(0.98)$ & $-0.87(0.68)$ & $0.80(0.52)$ & Pacific center variable & +1 std dev \\
\hline Sep & 5 & $1.22(0.58)$ & $-0.96(0.68)$ & $0.61(0.55)$ & southeast center weak & \\
\hline Oct & 5 & $0.73(0.93)$ & $-1.04(0.20)$ & $1.04(0.52)$ & Pacific center very variable & \\
\hline Nov & 5 & $1.37(0.76)$ & $-0.91(0.80)$ & $0.94(0.73)$ & all centers variable & \\
\hline Dec & 7 & $1.27(0.26)$ & $-1.30(0.35)$ & $1.25(0.60)$ & southeast center variable & \\
\hline
\end{tabular}

tion events in the time series; in other words, the distribution of precipitation may be significantly skewed. The gamma distribution (Thom 1958) has been shown to be very useful in normalizing precipitation data in several climatological studies (Ropelewski and Halpert 1986, 1989; Klein and Bloom 1987). Therefore, the mean monthly precipitation data used in this study were transformed to more normally distributed probabilities through the use of 344 separate-fitted gamma distributions for each month. Although some information is lost in any normalizing procedure, this step is necessary for the subsequent use of linear regression techniques.

The PNA index was then regressed against the standardized monthly temperature and precipitation for all 344 climatic divisions during the period of record 1947 through 1982 . The resulting correlation coefficients were mapped to show the regions of highest association for both temperature and precipitation. This analysis was completed on a monthly basis so that changes in the correlation patterns over the annual cycle could be observed.

For an individual climate division a correlation coefficient with an absolute magnitude greater than 0.35 $(N=36, \mathrm{df}=34)$ indicates a relationship significant at the $95 \%$ level using a two-tailed $t$-statistic for evaluation of correlation significance (Davis 1986). However, the finiteness and spatial autocorrelation of the temperature and precipitation data make estimation of the significance of the correlation field more difficult. Livezey and Chen (1983) recommend a two-step procedure for the evaluation of field significance. In the first step, the finiteness of the dataset is taken into account. All observations are assumed to be independent and a binomial distribution is used to estimate the per- centage of significance tests that must be passed in order to attain a field significance level of $95 \%$.

If the correlation field is judged significant after this test, the spatial autocorrelation present in the data must subsequently be accounted for because it can greatly effect the number of degrees of freedom actually present in the data. In general, Monte Carlo techniques must be used to estimate the percentage of passed significance tests needed to attain a field significance of $95 \%$. This percentage will usually depend on the type of data under consideration and the time period from which the data is attained.

In the present study all temperature correlation fields and the January, February, March, November, and December precipitation fields were judged significant at the $95 \%$ level using the technique described by Livezey and Chen (1983). The index-precipitation fields of the remaining months are also presented. Although there is a possibility that the fields not judged significant at the $95 \%$ level are an artifact of random chance, their relationship to the temperature correlation patterns and the ridge-trough positioning suggest a real physical relationship between the precipitation and the strength and phase of the PNA pattern.

In order to discern the positioning of the mean ridgetrough pattern associated with PNA index values for an individual month, the monthly index values were regressed against a 55-point grid of monthly mean 700 mb heights over North America. This technique yielded correlation fields for each month that showed the position of the ridge-trough system over the United States associated with opposite extremes of the index. These correlation fields (not shown) were used to aid in the interpretation of the PNA index-temperature/precipitation relationships. 


\section{PNA index-temperature correlations}

Contour maps of the correlations between the PNA index and United States temperature for each month are shown in Fig. 2. The January map reveals areas of high negative correlations over the southeastern United States and high positive values over the northwest. Between the area of high correlations is a strong gradient, with temperatures in the center of the country showing no important association with the PNA index. The reasons for this pattern are easily explained. The high negative correlations in the southeast are a result of below normal temperatures during years of positive index values and of above normal temperatures during negative index years. Positive index years, with their enhanced meridionality, have an anomalously deep trough over the southeast. This southerly displacement of the trough and the associated polar front jet allows continental polar and arctic air masses to move into the south more frequently, producing below normal temperatures. In addition, the amplified ridge over western North America favors the generation of strong cold-air outbreaks into the eastern United States because the ridge extends to higher latitudes over northwest Canada. During Januarys with negative index values, the polar front jet is displaced farther to the north than normal in the eastern United States, inhibiting the progress south of cold air masses and allowing the more frequent intrusion of maritime tropical air masses.

For Januarys in the northwestern United States, the enhanced ridging associated with positive index values denotes advection of maritime air into the western and northern parts of the region and some warming from subsidence directly under the ridge. Furthermore, the ridge steers North Pacific storms north of the area, thus, reducing cloud cover and inducing higher daytime temperatures. However, because the nights are longer during winter months, clear skies may lead to enhanced radiational cooling, offsetting the warming effects outlined above, especially in interior, high elevation areas. The effects are directly opposite when the index is negative, with nearly zonal westerly flow off the North Pacific directing a continual series of storms into the region. The northwest is then cooled by the abnormally high frequency of maritime polar air intrusions, sometimes augmented by Arctic air masses when the index is strongly negative, implying a ridge over the Gulf of Alaska and a trough over the western United States.

The correlation pattern for February is slightly weaker in the southeast, but is considerably stronger in the northwestern United States, possibly due to the fact that longer days favor more daytime warming to help offset radiational cooling losses with the clear skies of a positive index value. The physical mechanisms responsible for the January pattern continue to be important for February, although there is a tendency for the center of greatest negative correlation coefficient values to be farther to the east, implying a longitudinal expansion of the ridge-trough system. Since the PNA index really measures the phase and intensity of quasistationary Rossby waves over North America, this observed longitudinal expansion of the correlation pattern is likely a result of the small strengthening of the mean westerly flow from January through February (Rossby 1939; Barnston and Livezey 1987).

The opposite of this effect is evident in the March correlation field. The southeastern center of negative correlation shifts to the west, in association with a longitudinal compression of the ridge-trough system. This shortening of the stationary wavelength, and of the associated temperature correlations, is likely related to the weakening of the mean zonal flow at this time. During March, negative associations east of the Rockies are confined mainly to the southeastern United States and Texas. In the far west, the area of positive relationships is diminished.

The compressional trend apparent in the March pattern continues into April. The southeastern negative center has shifted westward to Louisiana and east Texas. Negative relationships now extend across the southern two-thirds of the United States east of the Rocky Mountains. The northwestern positive correlation center has apparently shifted northward, reducing the area of positive correlations in that region.

In May, a new trend in the direction of movement of the correlation patterns is evident. The configuration is broadly similar to April, but the southeastern center has now shifted north and slightly east. Except for New England, nearly all divisions in the eastern one-third of the country show strong negative correlation values. In the far west, the correlation gradient has an eastwest orientation with an increase in the area of positive correlations compared to April. The northward movement of the southeastern center may be associated with the northward displacement of the circumpolar vortex and its attendant Rossby waves. The strengthening of the positive correlations in the interior west may be related to radiative effects. As days grow longer than nights the enhanced daytime temperatures associated with clear skies during positive index months become more important than nighttime radiational cooling. This may lead to enhanced positive correlation values.

The September correlation configuration looks similar to that of May. The eastern center of negative correlations remains anchored in the southeastern United States. The western positive center is still centered in the Pacific Northwest, however, it is stronger than the May pattern.

The correlation pattern for October is unlike that of any other month with the isolines oriented nearly north-south and the correlation values changing smoothly from high positive values in the west to high negative values in the east. One explanation for this configuration is suggested by the work of Kalnicky (1987), who found that the months of October and 
January PNA-Temperature Correlations

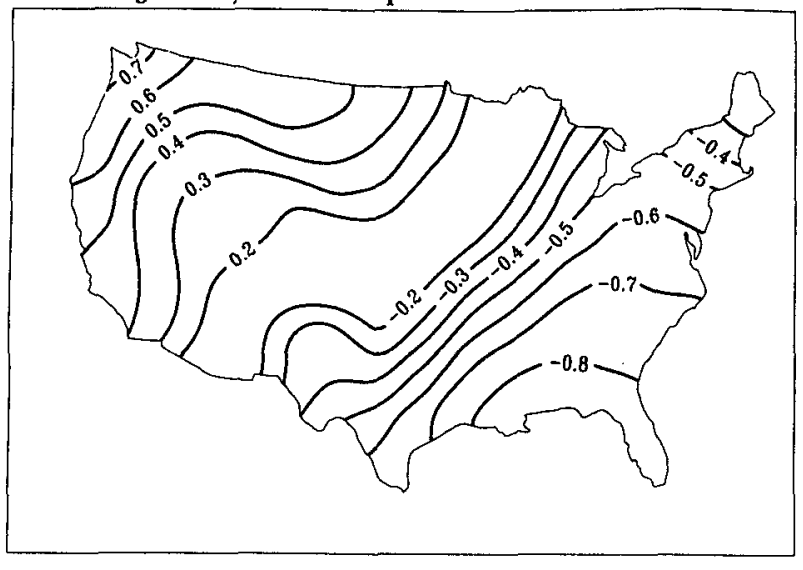

February PNA-Temperature Correlations

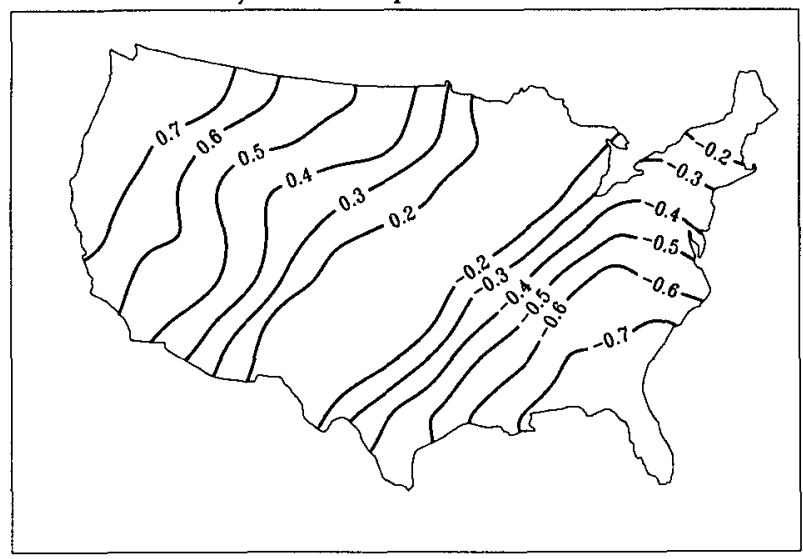

March PNA-Temperature Correlations

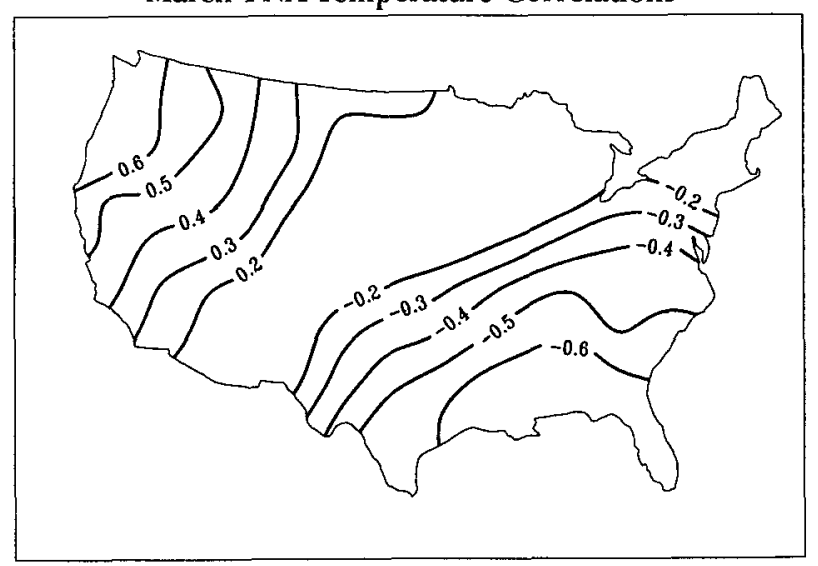

November were composed of circulation types reminiscent of both summer and winter, masking any coherent pattern for either month. The mix of circulation characteristics during this month may also account for

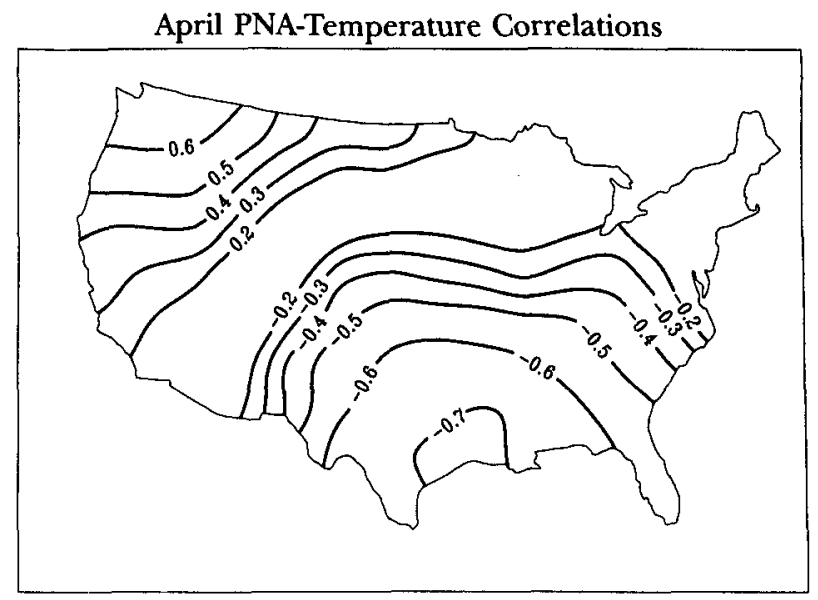

May PNA-Temperature Correlations

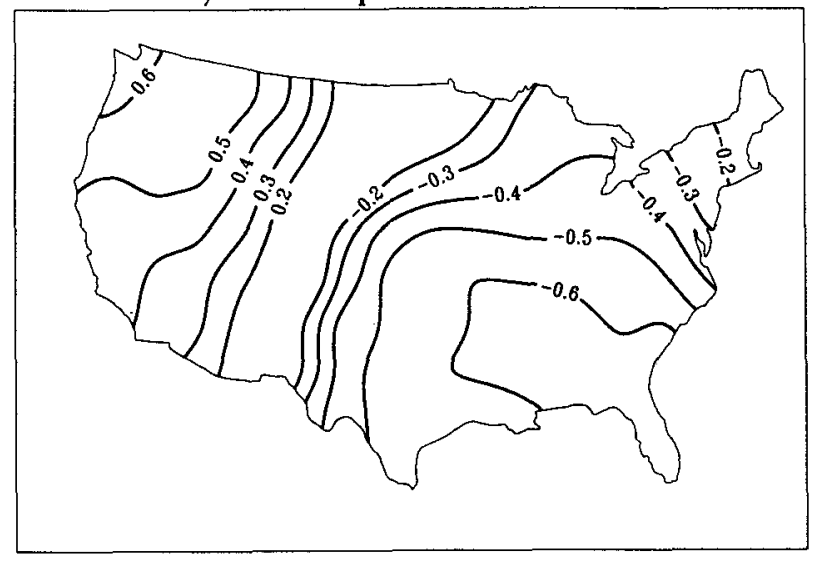

FIG. 2. Monthly maps of correlation coefficients between the PNA index and standardized divisional temperature.

the decrease in the absolute values of both the positive and negative correlation centers compared to the preceding or following months.

The November correlation pattern, although quite 
September PNA-Temperature Correlations

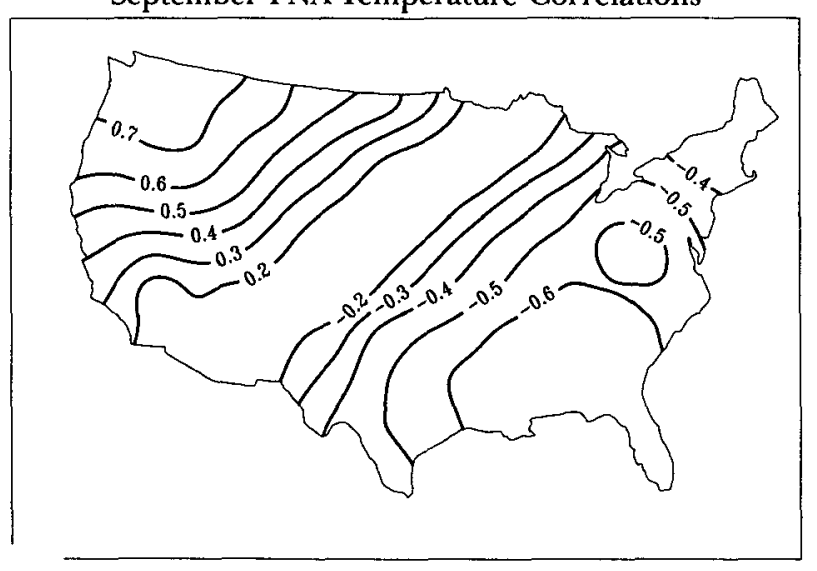

October PNA-Temperature Correlations

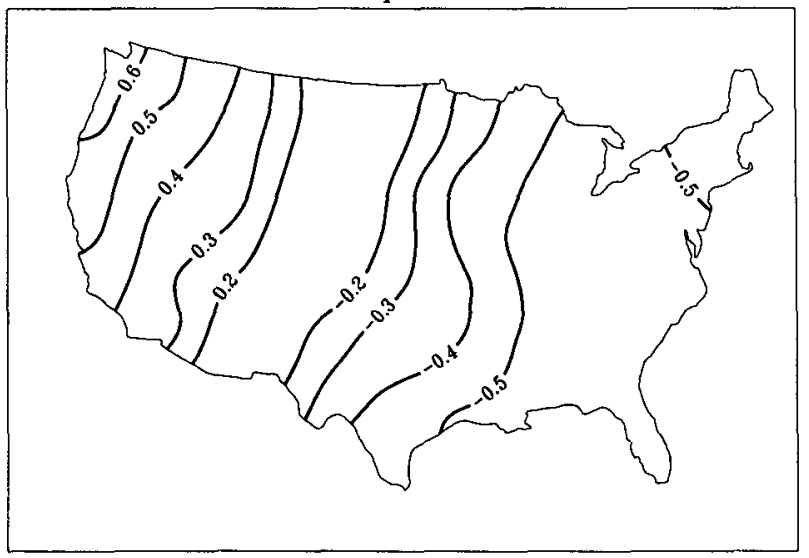

November PNA-Temperature Correlations

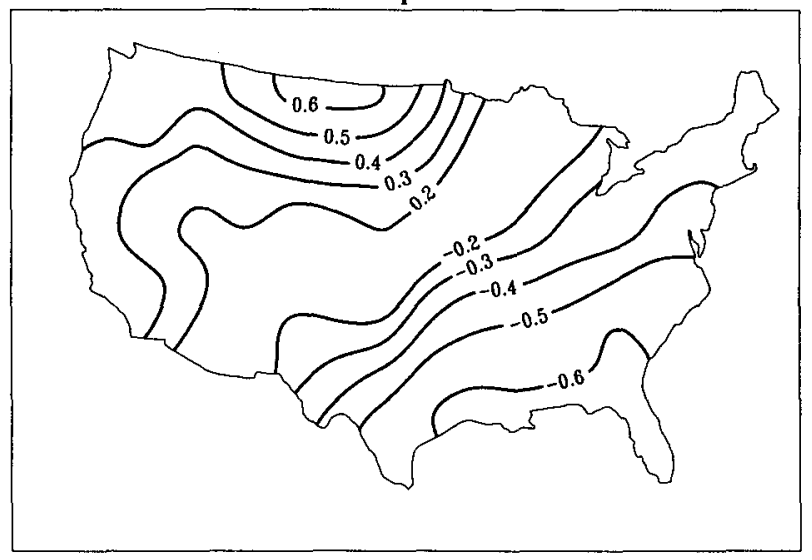

December PNA-Temperature Correlations

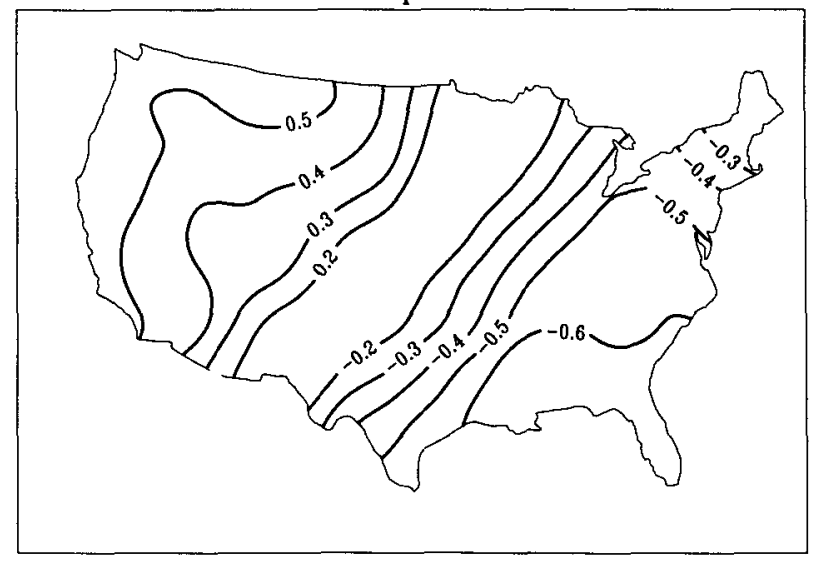

FIG. 2. (Continued)

different from October, is also unusual. The southeast center has moved to its winter position over the gulf coast region, but the northwest center is located relatively far to the east over eastern Montana and the Dakotas. This seems to suggest a longitudinal shrinking of the ridge-trough pattern during this month, opposite to the intuitive logic of typical Rossby wave dynamics. Still, the majority of the eastern United States temperatures are negatively related to the PNA index values, while the northern tier of the western half of the nation evidences positive relationships.

By December, the pattern has returned to the "normal" wintertime configuration with correlations similar to that of January and February. The correlation centers are again located over the southeast and northwest.

The most important conclusion to be reached from the maps of Fig. 2 is that the PNA teleconnection pattern, represented by the PNA index, is important in the specification of regional temperatures in most of the United States during those months of the year when the PNA is a main mode of midtropospheric variation.
The southeastern and northwestern United States show the highest correlations with more than $80 \%$ of the variation $(R>0.90)$ in temperature being explained by the index in some climatic divisions within these regions during the winter months. Although much of the country shows some association with the PNA during all months, the area of maximum correlation is dependent on the month of interest. The annual cycle of the correlation patterns suggest that the PNA indextemperature correlations tend to migrate with the position of the mean stationary waves, which are dependent on the strength and position of the circumpolar vortex and in some months on the strength of the subtropical highs in both the Atlantic and Pacific oceans.

\section{PNA index-precipitation correlations}

Monthly correlations between the PNA index and United States precipitation are mapped in Fig. 3. For a discussion of the significance of the patterns see section 3. 
January PNA-Precipitation Correlations

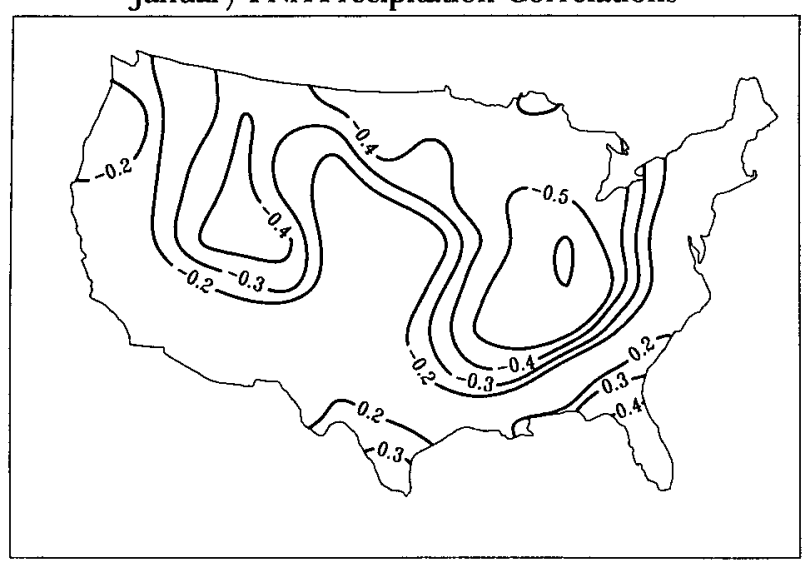

February PNA-Precipitation Correlations

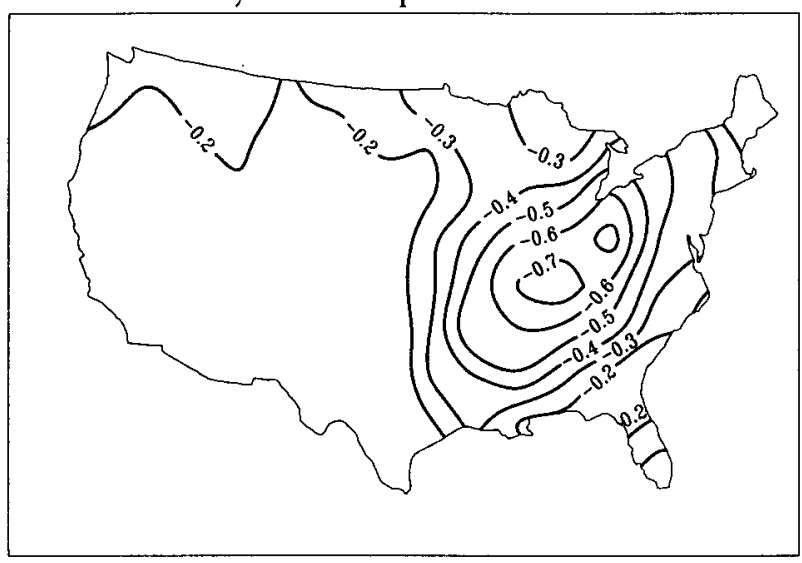

March PNA-Precipitation Correlations

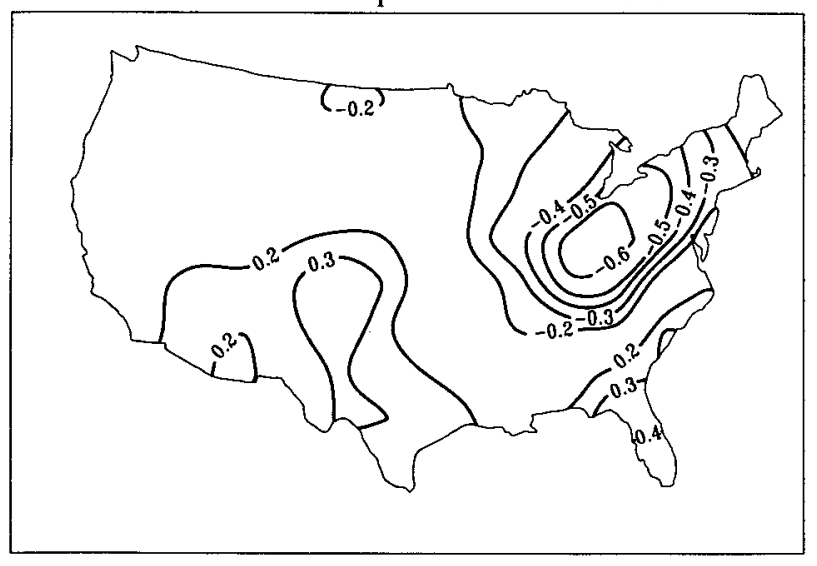

In the correlation pattern for January, areas of high association are evident over the upper Mississippi Valley and the northern Rockies. The position and sign of these regions of high correlations are physically rea-
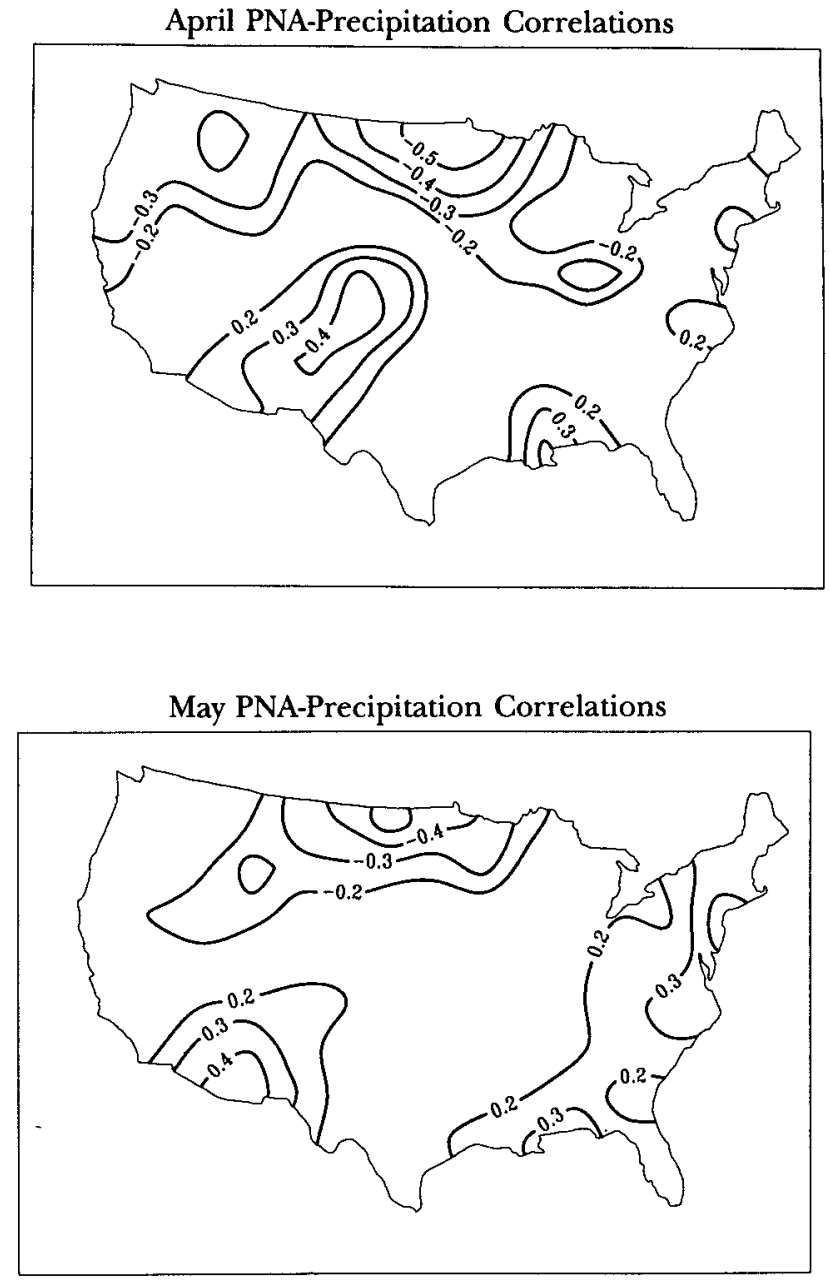

FIG. 3. Monthly maps of correlation coefficients between the PNA index and standardized divisional precipitation.

sonable. With positive index values, the deep eastern trough and associated polar front jet stream push far into the southeastern United States. Cyclones that form along the jet and their attendant precipitation will 
September PNA-Precipitation Correlations

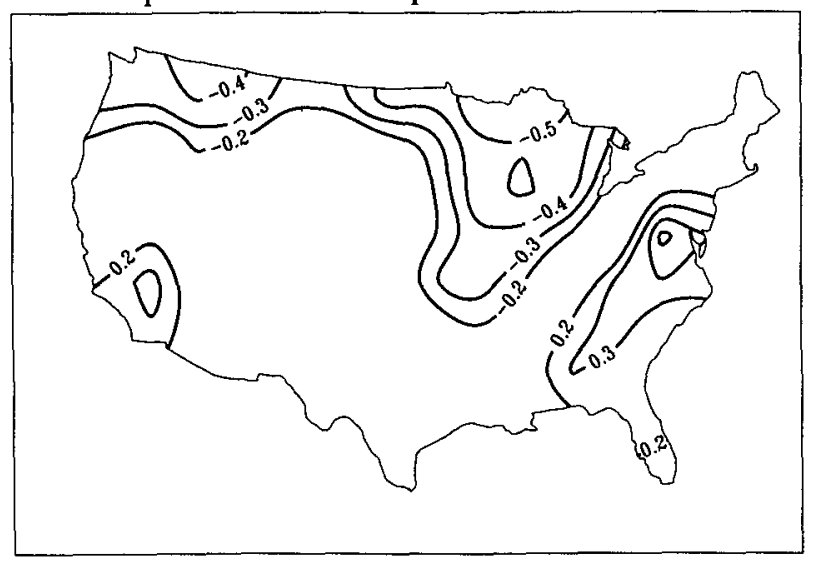

October PNA-Precipitation Correlations

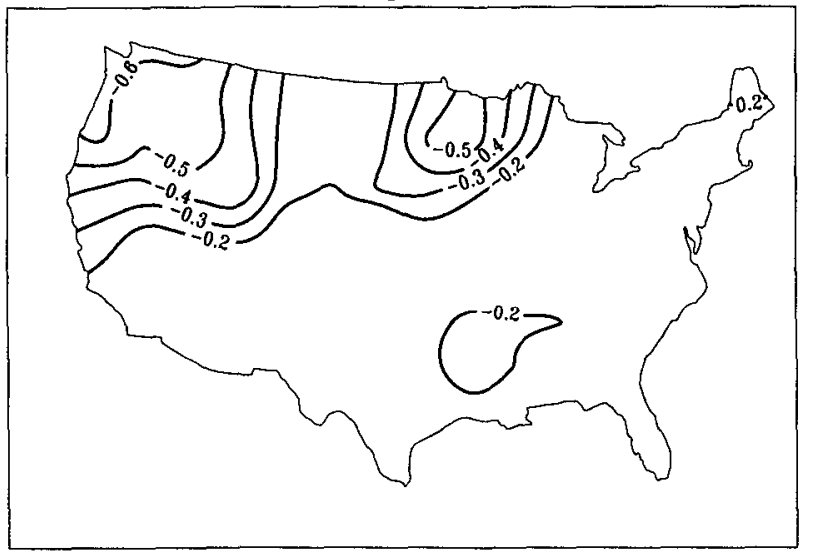

November PNA-Precipitation Correlations

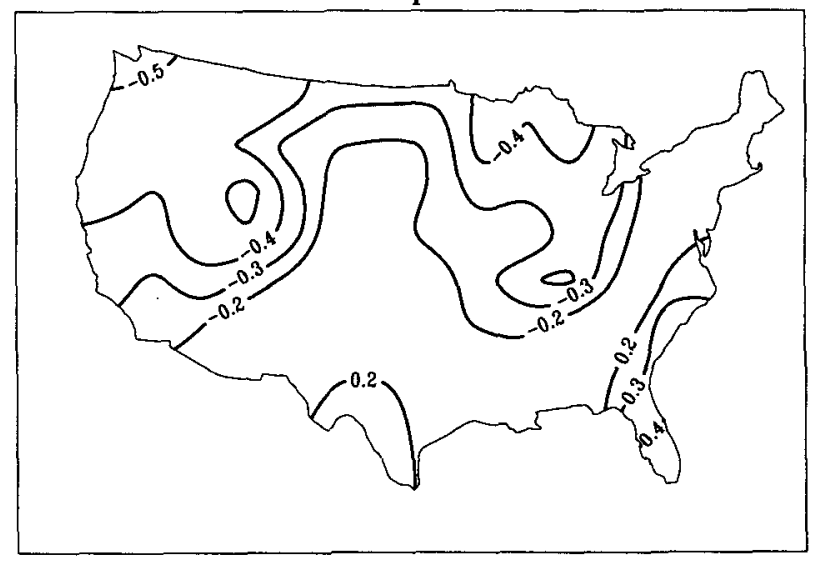

FiG. 3. (Continued)

therefore be farther south and east than usual, resulting in a decrease in precipitation amounts in the upper Mississippi Valley and Ohio Valley. This drying is enhanced by the polar and arctic continental air masses that dominate the region during periods of high positive index, effectively cutting off the moisture supply from the Gulf of Mexico. Over the Rockies, the anomalous ridge associated with a positive index value causes strong large-scale subsidence and compressional heating, both of which reduce precipitation amounts. Also, Pacific storms are forced north of the region, further decreasing precipitation totals.

With negative index values, the polar front jet is pushed far to the north of its mean position over the eastern part of the country. This allows maritime tropical air masses from the Gulf of Mexico to cover the area more often, increasing precipitation. In the west, the storm track is zonally oriented, bringing Pacific storms into the region more regularly and enhancing January precipitation totals.
The February correlation pattern is broadly similar to that of January in the eastern United States, but the area of high correlations over the Rockies no longer exists. East of the Rockies, the correlation maximum now lies along the Ohio Valley and is somewhat stronger than in January. The same physical mechanisms responsible for the January pattern remain important during February for the east; the lack of significant relationships in the west during this month is not easily explained in the context of the longwave configuration.

By March, the area of negative correlation values has decreased greatly in the east. During this month, only the vicinity immediately surrounding the Ohio Valley, and a small area in the southern Great Plains, show an important relationship between index values and precipitation. The area of high correlations in the former region is still consistent with the long-wave flow. The orientation of the positive isopleths in the southwest may suggest that a split flow develops during years of anomalous ridging (positive index years), with a 
southern storm track producing the increased precipitation amounts over the southern plains.

Although the precipitation correlation patterns for April, May, September, and October fall below the $95 \%$ significance level, they are physically reasonable given the accompanying 700-mb configuration. In April, the correlation pattern undergoes a major change. The negative correlation center in the Ohio Valley has moved north and west to Minnesota and the Dakotas in association with the weakening and northward displacement of the circumpolar vortex, while the region of positive correlations has strengthened and increased in size in the southwest. The negative values found in the upper Midwest and northern Great Plains seem to be a result of the intrusion of continental polar air during the positive phase of the index, while the increase in precipitation associated with negative index values may be related to the overrunning associated with an active zonally oriented storm track coming out of the Rockies into the High Plains. Again, a split flow, southerly storm track during positive index years seems to be the best explanation for the enhanced precipitation values over the High Plains and southwest.

May's pattern is similar to that of April, but weaker, with a very small area of negative PNA index-precipitation correlations in the north-central part of the country. In the southwest the positive correlation area has moved out of the southern Great Plains and into the Sonoran desert.

Two areas of the country show high correlation values between the index and precipitation during the first month of autumn. The first is an area of negative correlations located in the upper Mississippi Valley. This is probably related to the movement of continental polar air masses into this region, in association with the deepened eastern trough when PNA index values are positive, and vice versa for negative index values. The other area is one of positive correlation located along the mid-Atlantic coast, centered in northern Virginia, Maryland, and eastern West Virginia. During positive index months, when the eastern trough is located farther south and east than normal, the conditions along the south Atlantic coast are more favorable for coastal storm development (i.e., stronger temperature gradients, favorable upper-air patterns and greater airsea temperature differences; see Dickson and Namias 1976). With negative index values, the trough would be weaker and the jet would be displaced to the north making coastal storm development unlikely in this location.

As in the case of temperature, the October precipitation correlations may be the result of mixing summer and winter circulation types. Nevertheless, a large portion of the precipitation variance of the northern tier of the western United States is negatively associated with PNA index values during this month.

The correlation pattern for November seems to pick up the trend started in September, but interrupted by
October. Areas of negative correlations are apparent in the upper Mississippi Valley and over a large area of the western United States. This pattern is likely to be associated with the reestablishment of a strong ridgetrough system over the country, bringing drier continental polar air masses into the east and decreasing the precipitation in the west through the mechanisms described for January.

The December pattern is similar to November, but shifted slightly to the south in keeping with the climatological southward shift in the polar front jet and the associated stormtracks. Strong negative associations are evident in the Mississippi Valley and throughout the west, via the same mechanisms previously described for January.

To summarize, the results for the PNA index-precipitation correlations are encouraging. Because precipitation is usually a more localized phenomenon than temperature, especially during the warm season, it is much harder to quantify with large-scale circulation indices. Nevertheless, in all months considered, some area of the country displayed important relationships between the PNA index and precipitation.

\section{Conclusions}

The PNA index is highly correlated with monthly temperature and precipitation in many United States climatic divisions. Large areas of the country show significant index-temperature correlations in all months of the year in which the PNA is a major mode of atmospheric variability. The centers of highest correlation are generally located in the southeastern and northwestern United States, but migrate systematically with the strength and position of the circumpolar vortex and the jet stream position over the course of the annual cycle.

Areas with large correlations between the PNA index and precipitation are smaller and weaker than those for temperature. Nonetheless, these relationships are important to certain parts of the country at various times of the year, such as the Ohio River Valley in January, February, and March. Spatially coherent, synoptic-scale systems control precipitation during winter and early spring, with the result that those periods have the strongest, most extensive coverage of important correlations. In contrast, late spring and early fall precipitation is strongly influenced by smallerscale convective events (Throp and Scott 1982), so that these months have the least extensive and weakest correlations.

Thus, the Pacific/North American teleconnection is an important element in the climatic variability of many regions of the United States during those months when the pattern is a major mode of atmospheric variation in the Northern Hemisphere. In Part II of this study it will be demonstrated that PNA index variations are quasi-periodic with a broad spectral peak centered 
at 38 to $\mathbf{4 0}$ months, and that a large proportion of the variance in the PNA index is explained by a combination of sea surface temperatures in the equatorial Pacific, the North Pacific, and in the vicinity of southeast Asia, along with land and atmospheric variables from the Asian landmass.

This work and the study to be presented in Part II hint at many potential uses for teleconnections in climate studies. The empirical relationships between the upper atmosphere and the surface climate may be used in conjunction with the output of general circulation models to understand connections between changing global conditions and distinct regional climates. Many other teleconnection patterns are known to be major modes of low-frequency variation for spatially diverse areas of the globe, so that the technique used in this paper may be used with any stable teleconnection pattern in an effort to better understand the relationship between low-frequency atmospheric phenomena and surface climate variations. For example, work is currently underway relating the strength and phase of the main modes of Northern Hemisphere variability to temperature and precipitation across the United States for all months of the year at the climate division level. Preliminary results of this work have shown that several spatially diverse teleconnections play a role in regional climatic variability throughout the United States. Moreover, the interaction between spatially distinct teleconnections such as the NAO and PNA may be responsible for a significant portion of previously unexplained variance in surface climate variables (Yarnal and Leathers 1988).

Because of their relationship to regional climates, their spatial and temporal stability and their pervasiveness throughout the globe, teleconnections appear to be an as yet relatively untapped resource in the discussion of climatic change and variation. Ultimately, regional climatic variability is in large part a product of perturbations in the global climatic system transmitted by the PNA and other teleconnections.

Acknowledgments. The authors thank the Pennsylvania State University Earth System Science Center and its Director Eric Barron for their support toward the completion of this project. In addition, we acknowledge the Pennsylvania State University Department of Geography's Deasy Cartographic Lab for the preparation of the figures contained within the text. Finally, we thank Dr. Kenneth F. Dewey of the Department of Geography of the University of NebraskaLincoln for his comments on the manuscript and the helpful comments of the anonymous reviewers.

\section{REFERENCES}

Allen, R. A., R. Fletcher, J. Holmboe, J. Namias and H. C. Willet, 1940: Report on an experiment on five-day weather forecasting. Pap. Phys. Oceanogr. Meteor., 8, 94 pp.
Barnston, A. G., and R. E. Livezey, 1987: Classification, seasonality, and persistence of low-frequency atmospheric circulation patterns. Mon. Wea. Rev., 115, 1083-1126.

Barry, R. G., and A. H. Perry, 1973: Synoptic Climatology. Methods and Applications. Methuen and Co, $555 \mathrm{pp}$.

Bjerknes, J., 1966: A possible response of the atmospheric Hadley circulation to equatorial anomalies of ocean temperature. Tellus, 18, 820-829.

- 1969: Atmospheric teleconnections from the equatorial Pacific. Mon. Wea. Rev., 97, 163-172.

Blackmon, M. L., J. E. Geisler and E. J. Pitcher, 1983: A general circulation model study of January temperature anomaly patterns associated with interannual variation of equatorial Pacific sea surface temperatures. J. Atmos. Sci., 40, 1410-1425.

-, Y.-H. Lee and J. M. Wallace, 1984a: Horizontal structure of 500 -mb height fluctuations with long, intermediate, and short time scales. J. Atmos. Sci., 41, 961-979.

$\ldots, \ldots$ J. M. Wallace and H.-H. Hsu, 1984b: Time variation of 500-mb height fluctuations with long, intermediate, and short time scales as deduced from lag-correlation statistics. J. Atmos. Sci., 41, 981-991.

- R. A. Madden, J. M. Wallace and D. S. Gutzler, 1979: Geographical variations in the vertical structure of geopotential height fluctuations. J. Atmos. Sci., 36, 2450-2466.

Davis, J. C., 1986: Statistics and Data Analysis in Geology. John Wiley and Sons, $646 \mathrm{pp}$.

Dickson, R. R., and J. Namias, 1976: North American influences on the circulation and climate of the North Atlantic sector. Mon. Wea. Rev., 104, 1255-1265.

Emery, W. J., and K. Hamilton, 1985: Atmospheric forcing of interannual variability in the northeast Pacific Ocean: Connections with El Niño. J. Geophys. Res., 90, 857-868.

Esbensen, S. K., 1984: A comparison of intermonthly and interannual teleconnections in the $700-\mathrm{mb}$ geopotential height field during the Northern Hemisphere winter. Mon. Wea. Rev., 112, 20162032.

Frederikson, J. S., and R. C. Bell, 1987: Teleconnection patterns and the role of baroclinic, barotropic, and topographic instability. J. Atmos. Sci., 44, 2200-2218.

Geisler, J. E., M. L. Blackmon, G. T. Bates and S. Munoz, 1985: Sensitivity of January climate response to the magnitude and position of equatorial Pacific sea surface temperature anomalies. J. Atmos. Sci., 42, 1037-1049.

Gutzler, D. S., R. D. Rosen, D. A. Salstein and J. P. Peixoto, 1988: Patterns of interannual variability in the Northern Hemisphere $850 \mathrm{mb}$ temperature field. J. Climate, 1, 965-997.

Held, I., and I.-S. Kang, 1987: Barotropic models and the extratropical response to El Niño. J. Atmos. Sci., 44, 3576-3586.

Horel, J. D., and J. M. Wallace, 1981: Planetary-scale atmospheric phenomena associated with the Southern Oscillation. Mon. Wea. Rev., 109, 813-829.

Hoskins, B. J., and D. J. Karoly, 1981: The steady linear response of a spherical atmosphere to thermal and orographic forcing. $J$. Atmos. Sci., 38, 1179-1196.

Jenne, R., 1975: Datasets for meteorological research. National Center for Atmospheric Research Technical Note NCAR-TN/IA-111, Boulder, CO, $194 \mathrm{pp}$

Kiladis, G. N., and H. F. Diaz, 1989: Global climatic anomalies associated with extremes in the Southern Oscillation. J. Climate, 2, 1069-1090.

Karl, T. R., C. N. Williams, P. J. Young and W. M. Wendland, 1986: A model to estimate the time of observation bias associated with monthly mean maximum, minimum, and mean temperatures for the United States. J. Climate Appl. Meteor., 25, 145-160.

Kalnicky, R. A., 1987: Seasons, singularities, and climatic changes over the midlatitudes of the Northern Hemisphere 1899-1969. J. Climate Appl. Meteor., 26, 1496-1510.

Klein, W. H., 1952: Some empirical characteristics of long waves on monthly mean charts. Mon. Wea. Rev., 80, 203-219.

, and J. M. Kline, 1984: The synoptic climatology of monthly mean surface temperature in the United States during winter 
relative to the surrounding $700 \mathrm{mb}$ height field. Mon. Wea. Rev., 112, 433-448.

- and H. J. Bloom, 1987: Specification of monthly precipitation over the United States from the surrounding $700 \mathrm{mb}$ height field. Mon. Wea. Rev., 115, 2118-2132.

Lamb, P. J., and R. A. Peppler, 1987: North Atlantic Oscillation: Concept and an application. Bull. Amer. Meteor. Soc., 68, 12181225.

Lau, K.-M., and H. Lim, 1984: On the dynamics of equatorial forcing of climate teleconnections. J. Atmos. Sci., 41, 161-176.

large-scale circulation: A diagnostic study. Mon. Wea. Rev., 115, 400-428.

Lau, N.-C., 1985: Modeling the seasonal dependence of the atmospheric response to observed El Niños in 1972-76. Mon. Wea. Rev., 113, 1970-1996.

- 1988: Variability of the observed midlatitude stormtracks in relation to low-frequency changes in the circulation pattern. $J$. Atmos. Sci., 45, 2718-2743.

- and E. D. Holopainen, 1984: Transient eddy forcing of the time-mean flow as identified by quasi-geostrophic tendencies. J. Atmos. Sci., 41, 313-328.

Leathers, D. J., 1991: Low-frequency atmospheric variations and Great Plains climate: Interannual to interdecadal associations. $J$. Great Plains Research, in press.

--, and M. A. Palecki: The Pacific-North American teleconnection pattern and United States climate. Part II: Temporal characteristics and index specification. $J$. Climate, submitted.

Livezey, R. E., and W. Y. Chen, 1983: Statistical field significance and its determination by Monte Carlo Techniques. Mon. Wea. Rev., 111, 46-59.

—, and K. C. Mo, 1987: Tropical-extratropical teleconnections during the Northern Hemisphere winter. Part II: Relationships between monthly mean Northern Hemisphere circulation and proxies for tropical convection. Mon. Wea. Rev., 115, 31153132.

- , and A. G. Barnston, 1988: An operational multifield analogantilog prediction system for United States seasonal temperatures. 1: System design and winter experiments. J. Geophys. Res., 93, 10 953-10 974.

Mo, K. C., and R. E. Livezey, 1986: Tropical-extratropical geopotential height teleconnections during the Northern Hemisphere winter. Mon. Wea. Rev., 114, 2488-2515.

Nakamura, H., M. Tanaka and J. M. Wallace, 1987: Horizontal structure and energetics of Northern Hemisphere wintertime teleconnection patterns. J. Atmos. Sci., 44, 3377-3391.

Namias, J., 1969: Seasonal interactions between the North Pacific Ocean and the atmosphere during the 1960s. Mon. Wea. Rev., 97, 173-192.

- 1976: Some statistical and synoptic characteristics associated with El Niño. J. Phys. Oceanogr., 6, 130-138.

- 1978: Multiple causes of the North American abnormal winter 1976-77. Mon. Wea. Rev., 106, 279-295.

NOAA, 1983a: State, regional, and national monthly and annual temperatures, weighted by area, January 1931-December 1983. Historical Climatology Series 4-1, National Climatic Data Center, $68 \mathrm{pp}$.

_ 1983b: State, regional, and national monthly and annual total precipitation, weighted by area, January 1931-December 1983. Historical Climatology Series 4-2, National Climatic Data Center, $68 \mathrm{pp}$.
O'Connor, J. F., 1969: Hemispheric teleconnections of mean circulation anomalies at 700 millibars. Environmental Science Services Administration Tech. Rep. WB10, Silver Spring, Maryland, $103 \mathrm{pp}$.

Palmer, T. N., and D. A. Mansfield, 1986a: A study of wintertime circulation anomalies during past El Niño events using a highresolution general circulation model. I: Influence of model climatology. Quart. J. Roy. Meteor. Soc., 112, 613-638.

- , and D. A. Mansfield, 1986b: A study of wintertime circulation anomalies during past El Niño events using a high-resolution general circulation model. II. Variability of the seasonal mean response. Quart. J. Roy. Meteor. Soc., 112, 639-660.

Pitcher, E. J., M. L. Blackmon, G. T. Bates and S. Munoz, 1988: The effect of north Pacific sea surface temperature anomalies on the January climate of a general circulation model. J. Atmos. Sci., 45, 173-188.

Ropelewski, C. F., and M. S. Halpert, 1986: North American precipitation and temperature patterns associated with the El NiñoSouthern Oscillation (ENSO). Mon. Wea. Rev., 114, 2352-2362. , and M. S. Halpert, 1987: Global and regional scale patterns associated with the El Niño-Southern Oscillation. Mon. Wea. Rev., 115, 1606-1626.

, and M. S. Halpert, 1989: Precipitation patterns associated with the high index phase of the Southern Oscillation. J. Climate, 2, 268-284.

Rossby, C.-G., 1939: Relation between variations in the intensity of the zonal circulation of the atmosphere and the displacements of the semi-permanent centers of action. J. Mar. Res., 2, 3855.

Simmons, A. J., 1982: The forcing of planetary wave motion by tropical diabatic heating. Quart. J. Roy. Meteor. Soc., 108, 503534.

_ J. M. Wallace and G. W. Branstator, 1983: Barotropic wave propagation and instability and atmospheric teleconnection patterns. J. Atmos. Sci., 40, 1363-1392.

Thom, H. C. S., 1958: A note on the gamma distribution. Mon.Wea. Rev., 86, 117-122.

Throp, J. M., and B. C. Scott, 1982: Preliminary calculations of average storm duration and seasonal precipitation rates for the northeast sector of the United States. Atmos. Environ., 16, 17631774.

Wallace, J. M., and D. S. Gutzler, 1981: Teleconnections in the geopotential height field during the Northern Hemisphere winter. Mon. Wea. Rev., 109, 784-812.

- , and N.-C. Lau, 1985: On the role of barotropic energy conversions in the general circulation. Advances in Geophysics, Vol. 28A, Academic Press, 33-74.

Webster, P. J., 1981: Mechanisms determining the atmospheric response to sea surface temperature anomalies. J. Atmos. Sci., 38, 554-571.

, 1982: Seasonality in the local and remote atmospheric response to sea surface temperature anomalies. J. Atmos. Sci., 39, 4152.

Yarnal, B. M., and H. F. Diaz, 1986: Relationships between extremes of the Southern Oscillation and the winter climate of the AngloAmerican Pacific coast. J. Climatol., 6, 197-219.

, and D. J. Leathers, 1988: Relationships between interdecadal and interannual climatic variations and their effect on Pennsylvania climate. Ann. Assoc. Amer. Geogr., 78, 624-641. 